\title{
THE SPREAD OF RHEUMATIC FEVER THROUGH FAMILIES
}

By JOHN R. PAUL AND ROBERT SALINGER

(From the Departments of Internal Medicine and Pediatrics, Yale University; the New Haven Dispensary, and the Children's Community Center, New Haven)

(Received for publication November 11, 1930)

A number of epidemiological studies on rheumatic fever have been made, but in this disease, this field of endeavor is in its infancy as compared with other lines of approach. It has seemed to us, however, that here is another valuable weapon which may be brought to bear, not only because we would like to know more about the epidemiology of rheumatic fever, but it may tell us more about the nature of this obscure disease.

Knowledge concerning the actual distribution and spread of human disease, that is, its epidemiology is obtained in two ways: by direct observation, and by statistical methods, the latter being wholly dependent upon the former. There has been no dearth of direct observations of one sort or another in rheumatic fever, but in spite of them, actual facts which lend themselves to statistical analyses along epidemiological lines are few. The difficulties seem to lie primarily in the nonspecific character of many of the clinical aspects of this disease. Some of its forms seem to be recognized with reasonable accuracy, but unfortunately no specific test has yet been devised to tell us when an individual actually has rheumatic fever, and we are thus unable to determine its true incidence or distribution.

With these limitations in mind we have made an attempt to study the spread of rheumatic fever through families, as an epidemiological problem. We have chosen the family as a unit for study, (a) because it represents a small group in which an intimate investigation may be carried out; and (b), because one of the striking things about rheumatic fever is its high familial incidence, of which there is ample evidence (1) (2) (3). Cohn (4) has assembled figures obtained by different observers on this point and calls attention to the fact that in so-called rheumatic families, 8-10 per cent of exposed persons are 
infected, as against 2.9 per cent in the families of healthy controls. Perhaps the most cogent observation with regard to the familial incidence of rheumatic fever is that of St. Lawrence (2), who found a close resemblance to the familial incidence of tuberculosis. We do not know, however, the relative importance of certain factors which may be responsible for this high familial incidence, such as: (a), an hereditary predisposition to the disease; (b), common living conditions which favor its development; or (c), direct contagion as a result of intimate contact. Such problems are in themselves so complex that our study of them can only be regarded as a preliminary form of attack in which we have begun with a single aim: namely to observe the relationship as regards time of onset, which multiple cases within a given family bear to one another.

\section{METHODS}

The family approach. The idea of considering the family as a unit through which disease may spread is a concept which has proved of increasing value in the study of human disease. In the family one finds a concentration of common hereditary and environmental conditions in a group of individuals who are not only living in intimate contact with one another, but who are generally quite conscious of their group life. In the study of tuberculosis this approach has proved to be one of great value as emphasized by the work of Opie and his collaborators (5), and it is to this work that we are particularly indebted for our methods and concept of the subject.

Selection of families. Patients were largely selected from the Children's Cardiac Clinic of the New Haven Dispensary and from the Cardiac Division of the Children's Community Center of New Haven. ${ }^{1}$

In many instances individual children, generally accompanied by one of their parents, had been attending the Dispensary Clinic over a period of years and were consequently familiar with Hospital supervisory methods, making them a rather favorable group for the initiation of the study. Children rather than adults were primarily chosen for this work, because rheumatic fever generally makes its first appearance during childhood, and because a family of children has proved to be an easier group to handle for our purpose, than a family composed largely of adolescents and adults. These, however, were factors of choice, rather than of necessity and were not really of vital importance to our study.

${ }^{1}$ The clinic, which has been in operation since 1924, lists about 200 patients on its roll, 90 per cent of whom are suffering from rheumatic heart disease. The Cardiac Division of the Children's Community Center (established in 1926) is now under the active supervision of one of us (R.S.). About half of its patients have been drawn from the Heart Clinic of the New Haven Dispensary. 
A series of families were selected during the fall of 1928 in whom it was known that two or more members had at some time suffered from at least one of the manifestations of rheumatic fever. Selection was made on this basis because one of the main objects of the study was to observe the relationship which existed between attacks in two members of a family group. The material was further restricted to those families in which all the members had previously been under medical supervision, through the medium of the New Haven Hospital and Dispensary, for a reasonable period of years. Some of these records covered a period of twenty years. Particularly valuable in this respect were those families which had utilized the Dispensary as their "family doctor," so to speak, and had attended regularly for all trivial illnesses, as well as those of a more serious nature. As this Dispensary is the only general Dispensary at present in existence in New Haven, we were fortunate in having uniform and centralized records on this group of patients. Occasionally it was necessary to draw upon the records of other Hospitals ${ }^{2}$ in order to fill in certain gaps.

Method of family study. When all available records of past illnesses in one of the selected families had been secured, an appointment was made through the agency of a social service worker for a visit to the home of the family, with an explanation of the purpose of the visit and with special emphasis on the fact that the entire family group should be at home at the appointed hour. If any member of the family happened to be under the care of a practicing physician, the physician was either seen personally, or called on the telephone by one of us, in order to explain our reasons for questioning or examining his patient. Subsequently a copy of our findings on this and other members of the family was sent to the physician, if he so desired. A visit was then made by one of us to the home. The living quarters were inspected and investigated. Each member of the family who had not been seen in the Dispensary within a few weeks' time was submitted to a physical examination and adults were questioned with a view to the filling in of gaps in our records of their personal, social and past histories. Careful and exacting inquiries were made with regard to changes in the family environment, such as the sites of previous living quarters, and the dates on which the family had moved. Other members of the household who had become established as members of the family group, whether relatives or otherwise, were included in the studies. Subsequent to the initial visit the home was visited by one of us at intervals of two months, or more frequently if illness appeared in any member of the family group.

It will be seen that the attempt has been made to carry on the study in an intimate and personal manner, as we were anxious to establish close contact with the conditions under which the disease naturally develops, rather than to study patients who were isolated from their environment. Social workers ${ }^{3}$ have been

${ }^{2}$ We are particularly indebted to Mr. C. H. Dabbs, Superintendent of Grace Hospital, New Haven, for the privilege of examining some of the medical records of that institution.

${ }^{3}$ We are particularly indebted to Miss H. F. Alling for her assistance in this aspect of the work. 
utilized for the arrangement of appointments and for the gathering of non-medical data, but all visits made for purposes of ascertaining data on the health of the family, were made by one of us. This mass of detailed work has necessarily required the restriction of the families under supervision to a relatively small number, which to date numbers fifteen.

Charting results. In order to give a graphic representation of the life history of these families and of the incidents with which we have been concerned, a diagrammatic chart was designed for each family. The method of charting is shown in figure 1. This figure requires。a certain amount of explanation not shown on the diagram. On the right of the figure, the age of the family group, starting at the bottom with the birth of the parents, has been marked in decennial, biennial and annual periods, extending up to the point in time to which the study has been carried. The life span of each individual in the family is designated by the vertical columns inclosing space for the chronological tabulation of illnesses. Changes in family environment, as noted by change in address, are designated by horizontal lines; the removal of one individual from the family environment by enclosing the space about the life column.

On the left are the legends for tabulating illnesses. These are recorded as follows: the right side of the column is for the entry of the legends representing symptoms, signs, etc., which may or may not be related to rheumatic fever; the left side is for definite evidences of activity of rheumatic fever, shown as black blocks, varying in size according to our estimation of the degree and duration of the period of activity. The center of the life space is for the entry of rheumatic cardiac lesions, which we have come to recognize as one of the most important evidences of rheumatic fever now at our disposal. The first appearance of carditis has been designated in the form of a small Greek cross, and continued evidences of such a lesion, by a vertical line projecting from its top. The number of times which each individual has been seen by a physician at home, in the Dispensary, or in a Hospital, is shown by the black dots and rectangular figures aligned on the left of the life column. It is to be emphasized that these legends, marking the times which the patient has been under medical observation, do not always mean that a complete or even an adequate physical examination was performed at each visit. As a whole the dots represent the type of examination which is apt to be performed upon patients attending the various clinics of a Dispensary. Visits to the eye clinic for purposes of refraction, and to the dental clinic for the extraction of teeth, have not been included. 


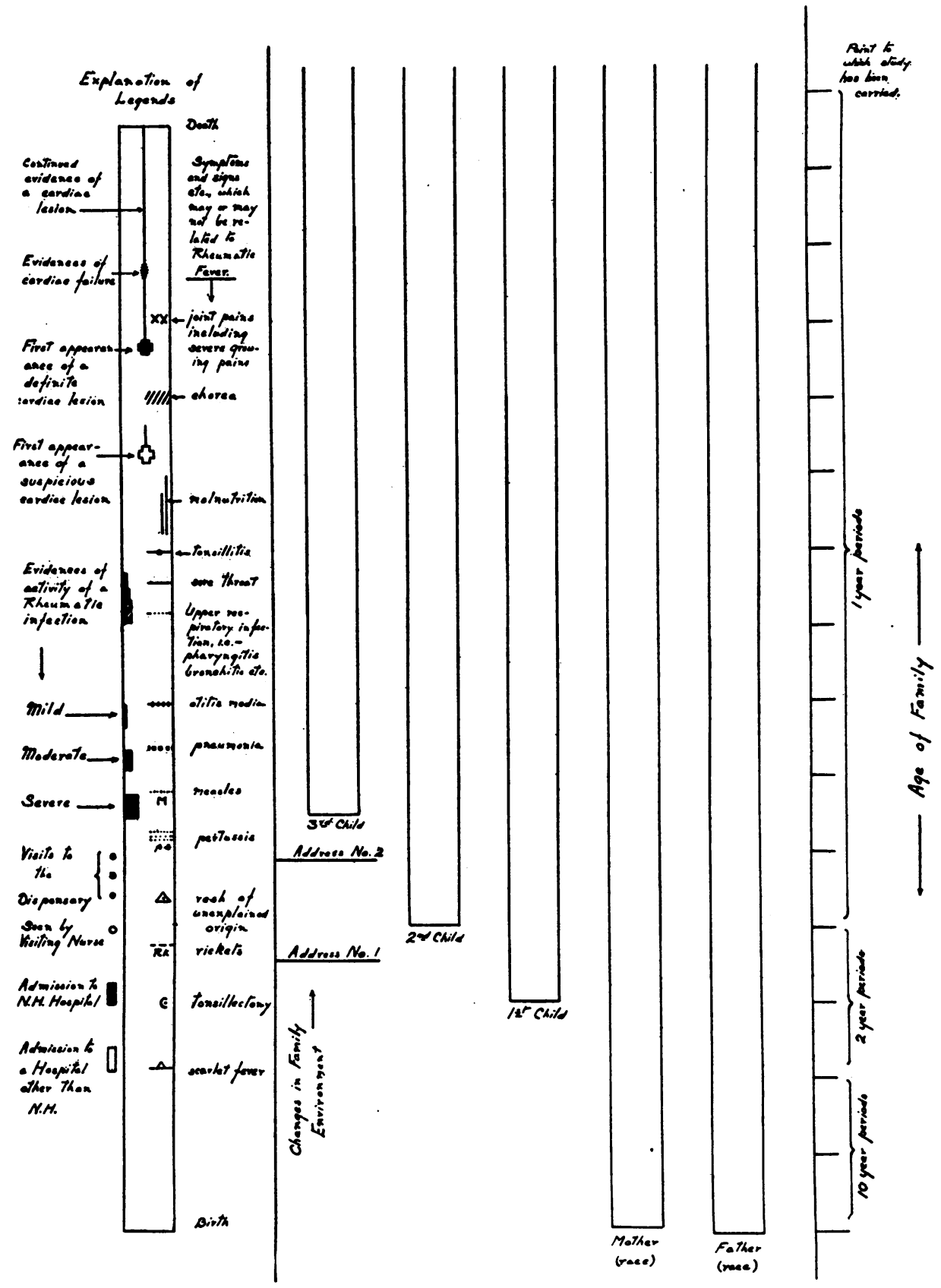

Fig. 1. Explanation of Chart for Recording Famity Data 


\section{RESULTS}

To date fifteen families have been subjected to the type of study outlined above, of which five examples are shown. In some, data have been reasonably complete, in others there are large gaps. A glance at the charts showing the number of times different members of the family have been under medical observation will give some idea of the degree of completeness with which the data have been gathered.

A repetition of the story of the illnesses experienced by each family will not be attempted for it can be ascertained from the chart. However, a few explanatory statements will be made to supplement the data on each chart.

In figure 2 (family 2-Mn.) are recorded the data from a family with four children. Unfortunately intimate knowledge of the history of both parents is lacking. The father, gave a clear cut history of having had what he was told was rheumatic fever when 10 years of age. At that time he was confined to bed with fever and joint pains for a period of months and was told that his heart was affected. During the subsequent twenty years he experienced no untoward symptoms and in recent years had been able to pursue the occupation of truck driver until October 1928, when he began to suffer from a sore throat lasting over a period of two months, accompanied by bouts of fever. When first examined in January 1929, he was still suffering from his throat infection and also showed an over-active heart and evidences of mitral stenosis. Subsequently he improved and has been without symptoms for more than a year. Coincident, or a few weeks previous, to the father's illness the oldest child began to suffer from joint pains, loss of weight, bronchitis, and on two examinations a systolic murmur was detectable, which was not present in subsequent examinations. In December 1929, also coincident with his father's and sister's illness, the younger brother (William) developed outspoken evidences of rheumatic infection with carditis which persisted for a year. He was removed from the family environment and has been subsequently kept at the Children's Community Center.

We have, therefore, three more or less synchronous attacks of illness in this family, two of which represent probable periods of activity of rheumatic fever and one of which (William) represents a definite period of rheumatic activity. In the father the illness was a recurrence; in the two children the illness probably represented the first manifestations of rheumatic fever. 


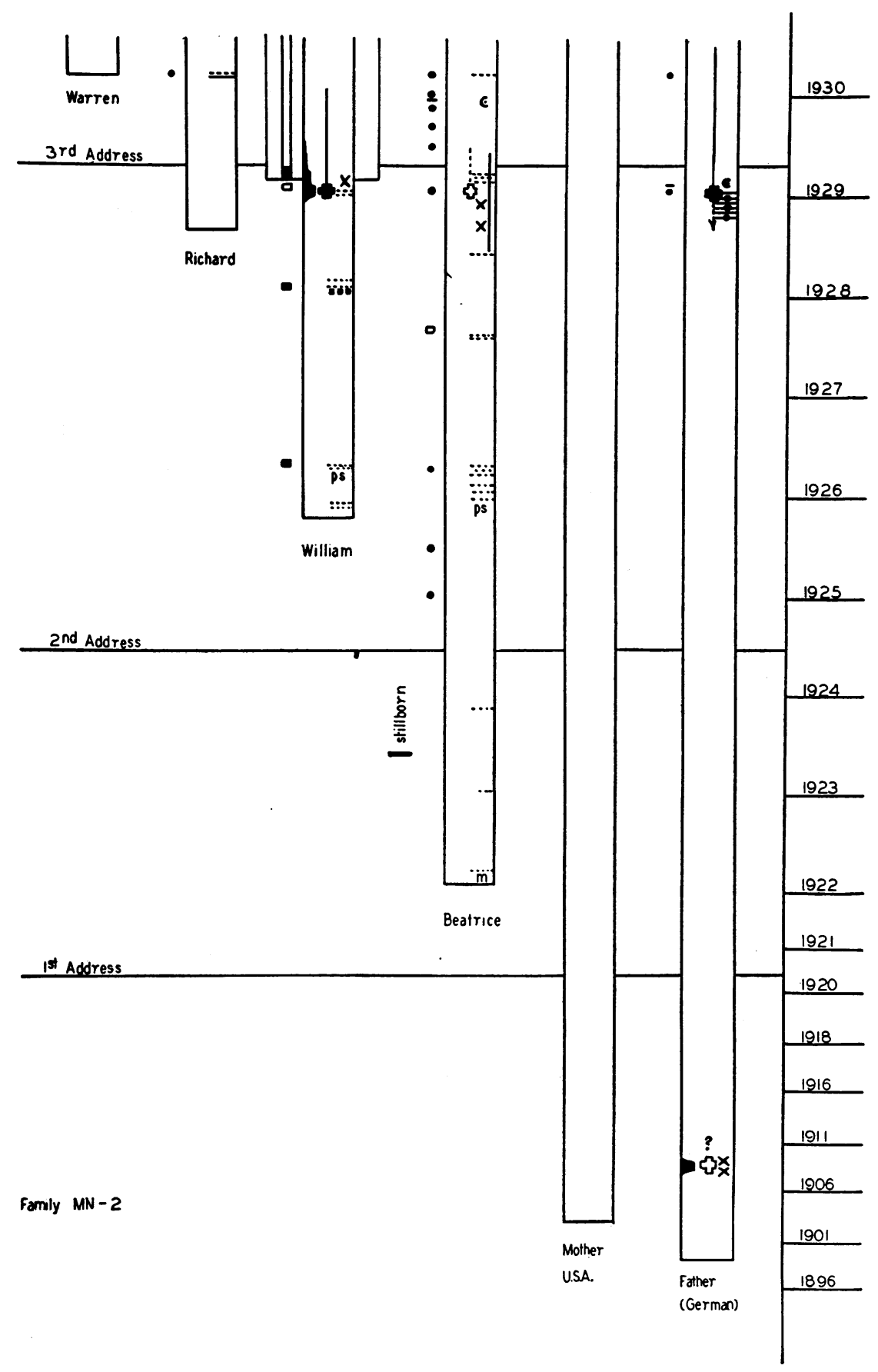

FIg. 2. FAMILY 2 
Figure 3 (family 4-Ds). Both of the parents were Jewish and had apparently lived at the same address since the birth of the first child. They were poverty stricken and lived practically in one room during this entire time. In 1925, Jacob, the fourth child, developed rheumatic fever and was admitted twice to the New Haven Hospital. Evidences of severe carditis did not appear until six months after his initial attack, but were severe enough to require his removal to a Cardiac Home. Interestingly enough at about this time a mitral lesion was picked up in the mother, although repeated previous examinations during her visits to the Dispensary for prenatal and other types of care, had failed to reveal this finding. No other members of the family showed evidences of rheumatic fever during the two years subsequent to its first appearance. However, in the fall of 1928 the mother entered the hospital with a flare-up of her infection, suffering from severe carditis and cardiac failure. At the time of her admission she had been suckling Abie, the eighth child-aged one year. He was also brought to the bospital with the mother, and found to be suffering from fever and a skin rash, originally thought to be measles. His illness was brief and no satisfactory diagnosis was reached. During the next year and a half, he was again admitted to the hospital; his next older brother, who slept at home in the same bed with him, was also admitted to the hospital three times during athis period, suffering from bronchitis and skin rashes of unexplained origin. Transient evidences of a suspicious cardiac lesion were picked up in both of these children in the course of the hospital studies.

We have in this family, observations on (a) an attack of rheumatic fever in one child (Jacob), associated with the appearance of signs of rheumatic carditis in the mother; and later $(b)$ the development of illness in two infants, one of which occurred synchronously with an attack of recurrent rheumatic fever in the mother. Whether the symptoms in these infants actually were those of rheumatic fever is questionable, but the balance of evidence would indicate that such was the case. 
JOHN R. PAUL AND ROBERT SALINGER

$\sqcup$
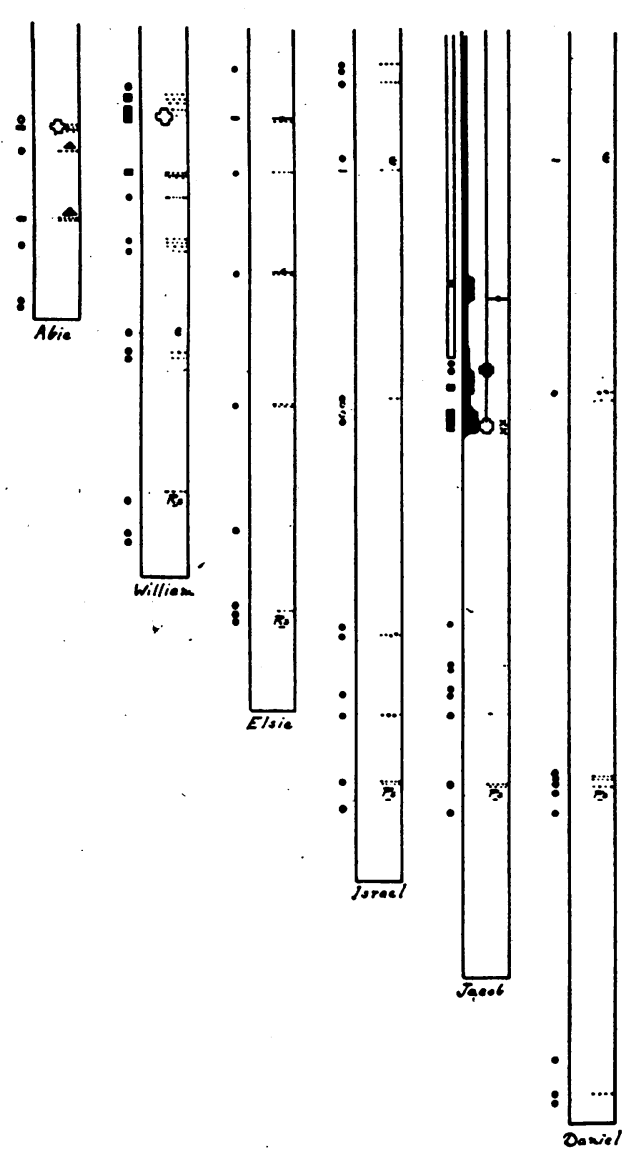

Fandy"

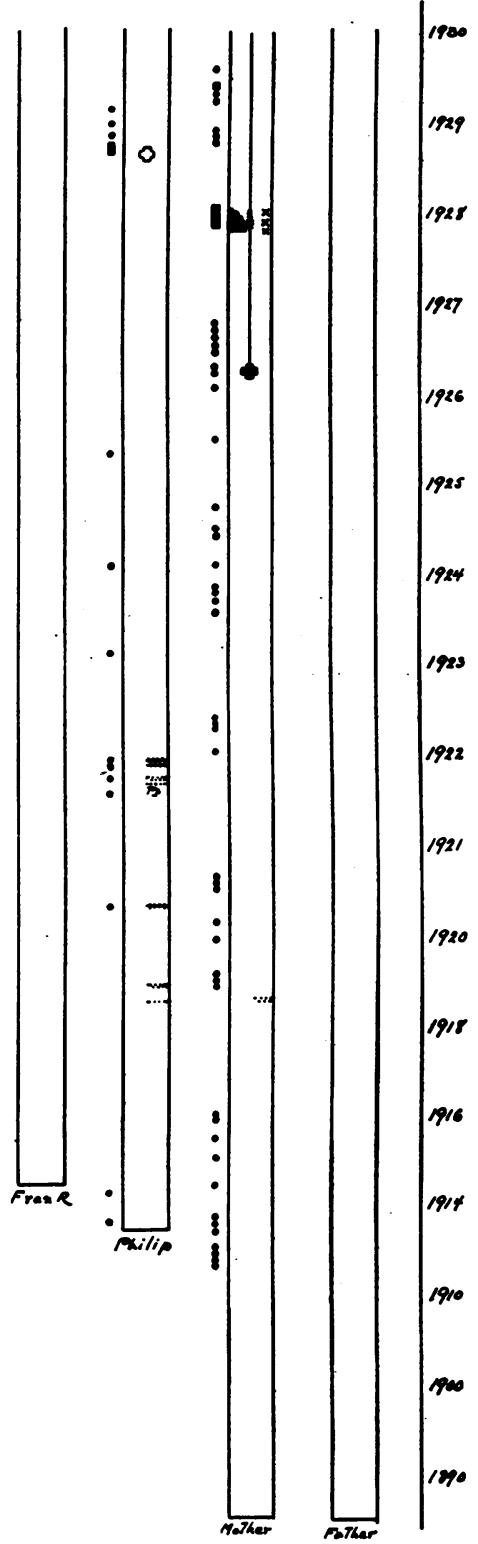

Fig. 3. FaMmI 4

THE JOURAN OF CLINICAL INVRETIGATION, VOL. $x$, NO. 1 
Figure 4 (family 12-Me). Both father and mother were French Canadians and in 1917, seven years after their marriage, had moved to New Haven from Chicopee, Mass. In 1921 the father, who was in the insurance business, died suddenly from what was thought to be Angina Pectoris. The family was left in rather straightened circumstances and became Dispensary patients about this time. As medical assistance had been previously rendered by private physicians we have no first hand records of the children's previous illnesses or examinations. In 1922, the three oldest children suddenly began to suffer from active manifestations of rheumatic fever, all within a period of six weeks. The fourth and youngest child also showed mild evidences of ill health, manifest by joint pains and loss of weight. The subsequent history of this family is relatively clearly shown upon the chart. The oldest boy enlisted in the United States Navy but was discharged unfit, after spending a large part of his time in the Hospital. The youngest girl has shown persistent evidences of malnutrition to date with occasional transient joint pains. It seems probable that she has been suffering from 'low grade rheumatic infection although the diagnostic criteria are perhaps not quite adequate.

The simultaneous onset in 1922, of what appear to be four cases in four children, is striking. 
JOHN R. PAUL AND ROBERT SALINGER

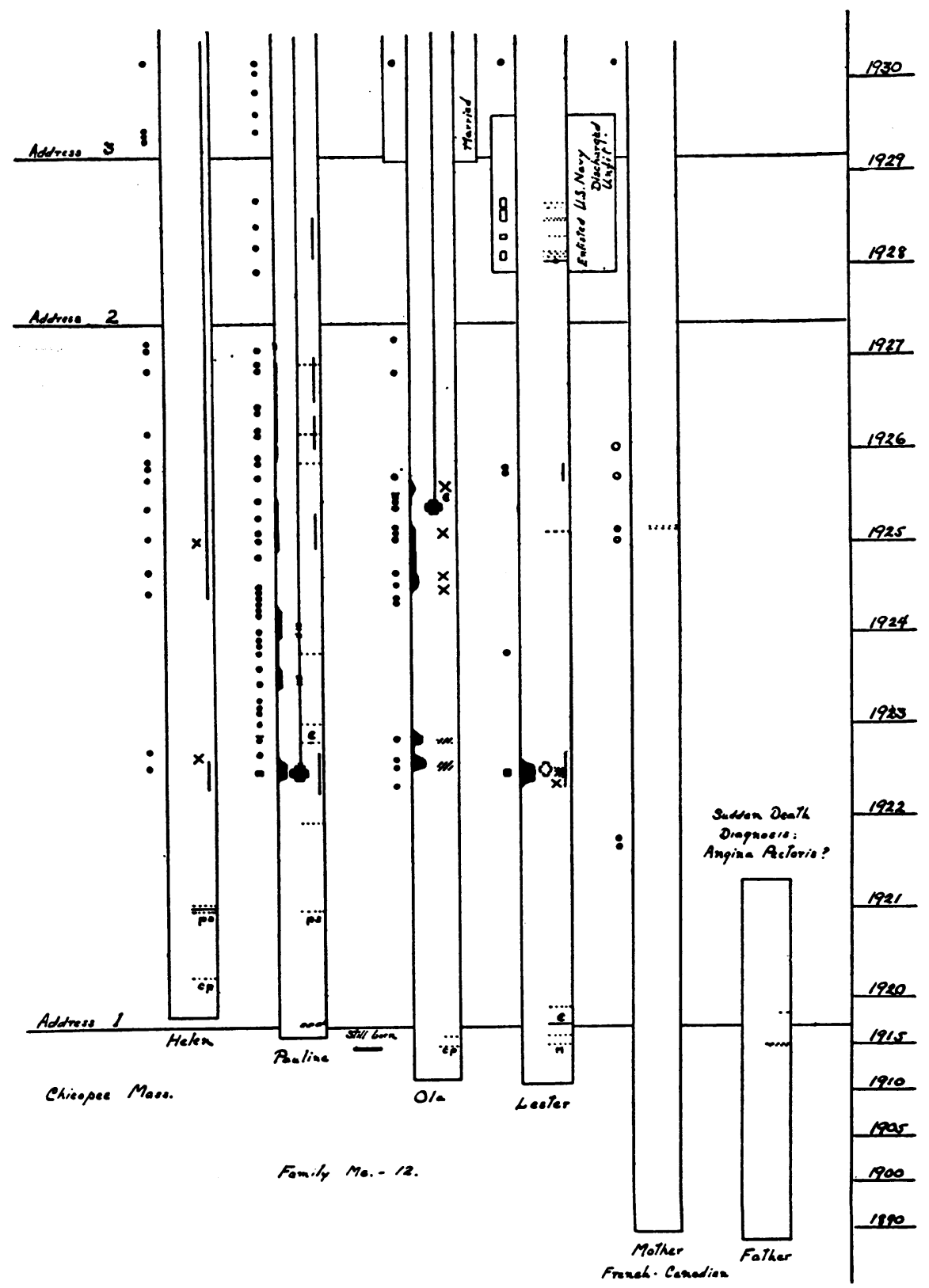

FIg. 4. FAMILY 12 
Figure 5 (Family 6-De Gn). Both father and mother were Italian. During their early married life they had shifted from one city address to another but had finally moved to the fifth address, a house on the outskirts of the city, because they thought their lodgings in town were unhealthy. It was at the town lodging (address no. 4) in 1922 that the first manifestation of rheumatic fever had appeared, in the form of a brief attack of chorea in the second child, and in the development of an early cardiac lesion in the third child. The three youngest children also suffered from what seemed to be minor illnesses at this time (1922); such as tonsillitis, bronchitis, and otitis media. Subsequently only one child has developed severe carditis but the three youngest children have developed suspicious cardiac lesions, one of them in an attack of recognizable rheumatic fever. It is also interesting that during the period when the children were showing evidences of low grade rheumatic fever the mother was being treated at the Dispensary for infectious arthritis.

It would seem, therefore, that in 1922 an epidemic of illness had swept through this family, which took the form of rheumatic fever in two children; in the others it might be logically described as upper respiratory infection. Subsequently some of the children in the latter group also seem to have developed rheumatic fever. 
JOHN R. PAUL AND ROBERT SALINGER

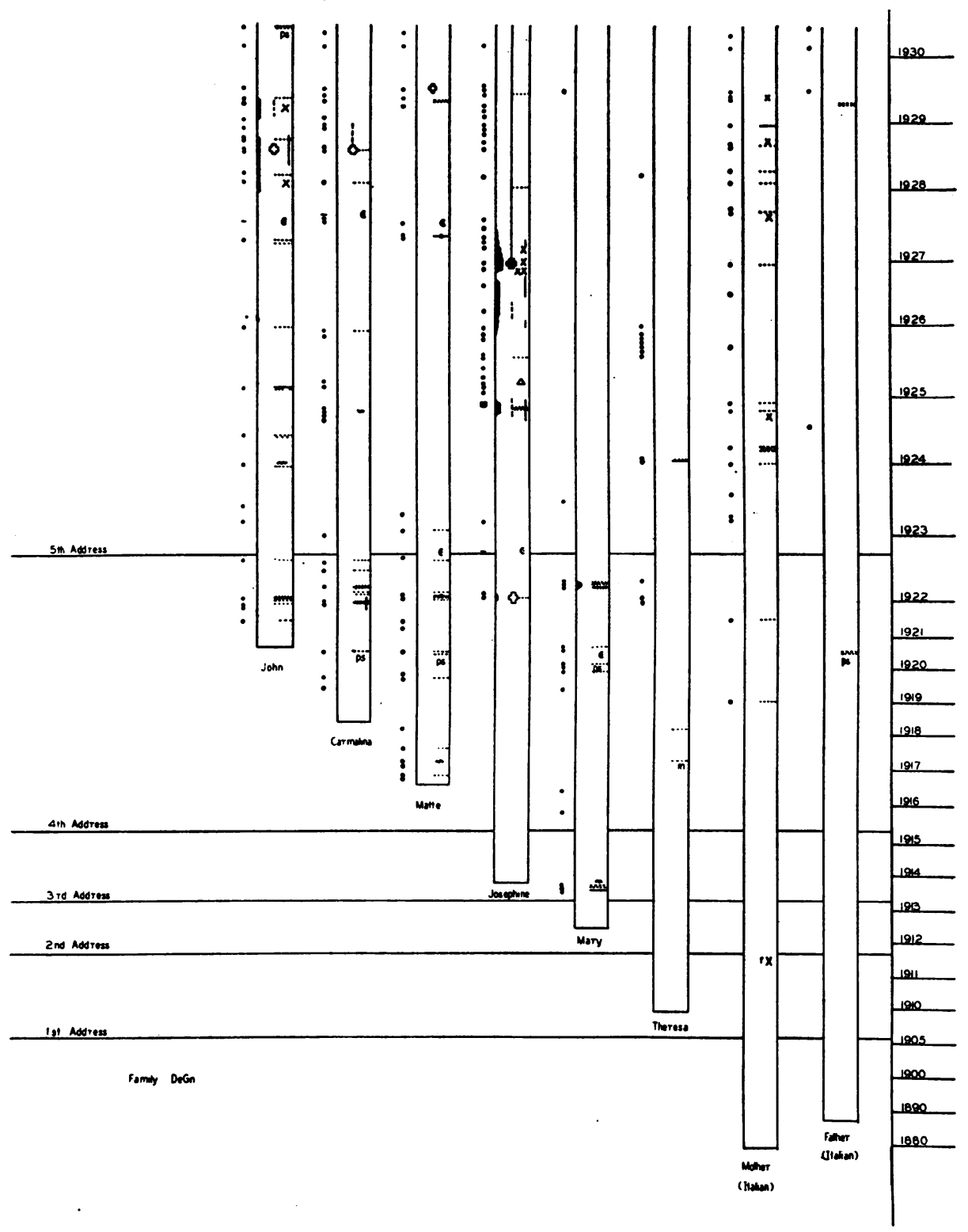

Fig. 5. Family 6 


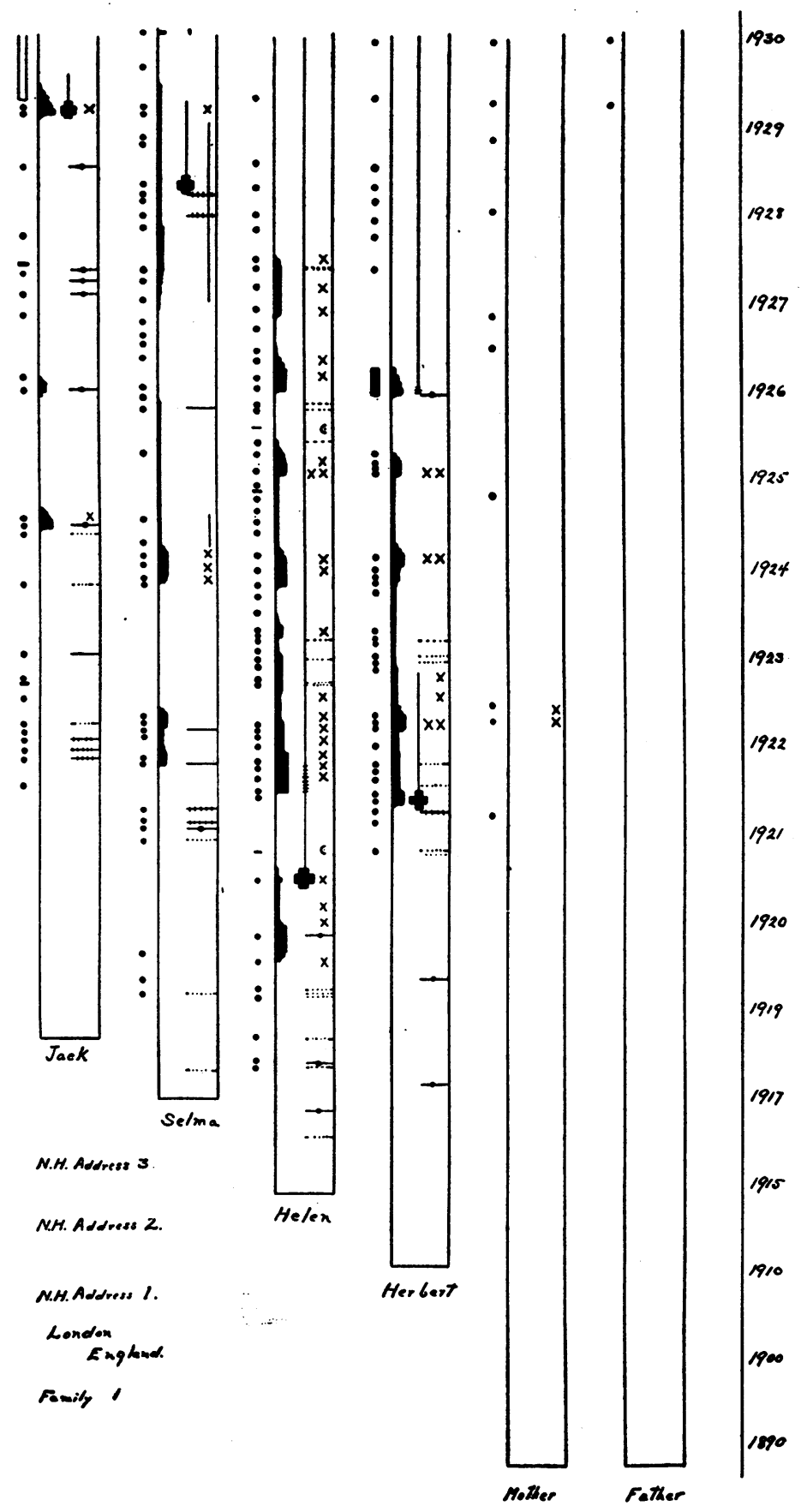

FIG. 6. FAMILY 1 
Figure 6 (family 1-By). A Jewish family which had emigrated from London to New Haven in 1914. In neither parent were there evidences of the disease. All of the four children have been under fairly close observation for at least 10 years; all had rheumatic fever, and all have cardiac lesions. In three the transient nature of cardiac signs are well shown.

An interesting feature in this group is that all of the children suffered from a series of rather severe, upper respiratory infections over a period of 2 to 6 years, prior to the development of recognizable evidences of rheumatic fever. Furthermore synchronous waves of illness have swept through this family from time to time in which two or more children have shown simultaneous periods of activity of their rheumatic infection. Interestingly enough, during one of these periods the mother was attending the New Haven Dispensary for an illness thought to be infectious arthritis.

\section{DISCUSSION}

Our observations have been made upon only fifteen families and are subject to many criticisms of which the most obvious is, that the historical data concerning certain of the individuals under observation are somewhat sketchy. Furthermore the interpretation of our findings may only apply to the conditions under which the study has been made, namely in families in which the incidence of the disease is high.

Our major aim was to observe the relationship as regards time of onset, which multiple cases within a given family bore to one another. The results indicate that the appearance of either primary or recurrent bouts of rheumatic activity in certain members of these families has been frequently accompanied by the almost simultaneous (or the immediately subsequent) appearance of the disease in other members of the family. This fact does not appear remarkable in view of the many reports of epidemics of rheumatic fever which have been recorded, in houses (6) (7) (8); in barracks (9) (10) (19); in schools (11) (12); and communities (13).

Another fact which has been observed is, that not only does the disease frequently make its first appearance almost simultaneously in several members of a given family, but periods of recurrent activity seem to sweep through a family in synchronous waves (cf. fig. 6). This latter observation is also in confirmation of a now fairly well recognized occurrence in juvenile rheumatic populations, namely, the epidemic manner in which severe flare-ups of rheumatic activity may 
occur. Boas and Schwartz (14) have described two such "epidemics" occurring in a ward of convalescent rheumatic children. Hiller and Graef (15) have also described a similar situation in a camp for children with rheumatic cardiac disease. These examples do not represent true epidemics of rheumatic fever in the sense that new cases suddenly appeared in a previously uninfected population. Rather they are examples of simultaneous periods of "reactivation" apparently following, after a definite interval, an epidemic of some upper respiratory infection. Our interest has been to differentiate such occurrences from the simultaneous appearance of new cases in a previously uninvolved population, although we have occasionally found difficulty in determining whether some of our cases actually occurred in virgin soil or not.

Still another interesting finding associated with these family epidemics has been the appearance of nonspecific types of illness, such as $(a)$ bronchitis, bronchopneumonia, skin rashes; and $(b)$ rheumatoid arthritis. The first group of conditions have been prone to appear in children who have not previously had rheumatic fever, often acting as a "precursor," so to speak of recognizable forms of the disease. Such phenomena might be explained on the basis of differing age and immunological expressions of the host to the rheumatic virus, for there are few diseases in which the age of the patient determines the clinical manifestations of the disease more than rheumatic fever, and it is to be recalled that in families such as the ones selected above we are dealing with groups of individuals of widely differing ages. It is also to be recalled that the limits of the clinical picture of this disease have not as yet been determined. Our epidemiological studies therefore offer an opportunity to broaden conceptions with regard to the clinical manifestations of this disease, particularly in what seem to be first attacks in very young children.

An interpretation of these observations from an etiological point of view offers certain complexities which do not readily lend themselves to analysis. However, previous evidence and the evidence furnished above, support the fact that rheumatic fever is an infectious disease. We recall, however, that an appreciation of the pathogenesis of this and other infectious diseases embraces at least three major factors: (i) the incitant; (ii) a susceptible host; (iii) paths which facilitate the 
bringing together of $i$ and ii. In rheumatic fever we are not sure of the nature of any of these three factors, although it would seem that the second factor: the nature of susceptibility, must be of the utmost import in this disease, and one which has led some investigators to champion rheumatic fever as a disease in which heredity plays an all important rôle (16) (17); and others to champion the rôle of environment (18). That environmental factors to which a whole family is exposed must be of some importance is shown by our observations that flare-ups of recurrent activity of the disease seem to sweep through a family in synchronous waves. Our findings are in accord with at least three current theories which have to do with susceptibility in this disease. (A) That crowding and the presence of any one of a variety of upper respiratory infections is the important factor in spreading the unknown virus by droplet infection (19). (B) That rheumatic fever is essentially an environmental disease (18); in which unknown factors, perhaps having to do with climatic conditions (20), housing conditions (21) (22), or nutritional factors (23), pave the way to development of an infection of unknown etiology. (C) That allergic phenomena elicited by bacteria, of the streptococcus group, may figure with great importance among the factors which predispose to the disease (18) (19). All three theories, together with the view that heredity ${ }^{4}$ plays an important predisposing rôle might fit in with the limited facts which we have observed, and their further elucidation must await more extensive observation.

Nevertheless whatever may be the true nature of certain hypothetical factors, which seem to be of great importance in predisposing to the disease, our results indicate that, given the conditions under which the disease seems to flourish, it acts epidemiologically like an infection, often producing explosive primary or recurrent outbursts of activity in several individuals, who may show extremely different types of host response. During these epidemic waves, and in rheu-

${ }^{4}$ An analysis of the rôle of heredity may be more satisfactorily approached when control studies of this type (which are now in progress) are directed against groups of unrelated individuals who are living in close proximity to one another. We have already found two tenement houses in New Haven in which manifestations of rheumatic fever have appeared, more or less simultaneously, in several children representing two different families. 
matic families in general, children between the ages of 4 and 12 seem to be particularly prone to develop the infection. The ages at which this susceptibility reaches its height and begins to diminish, will be discussed in a subsequent paper (26).

\section{SUMMARY}

1. The spread of rheumatic fever through families strongly suggests that we are dealing with an infection, in which the important rôle of environment, and of an hereditary predisposition to the disease, is as yet undetermined.

2. The sudden appearance of what seem to be both primary and secondary outbursts of rheumatic activity in certain individuals has been frequently accompanied by the appearance of recognizable forms of the disease in other members of the family group, and not infrequently by the simultaneous appearance of nonspecific types of illness such as bronchitis, bronchopneumonia, skin rashes, and rheumatoid arthritis. We have therefore an unusual opportunity to broaden our conception of the disease by this approach.

3. Not only do several cases seem to be initiated simultaneously, but periods of recurrent activity of the disease seem to sweep through a family in synchronous waves, during which time new cases may also appear.

4. These findings have been discussed in the light of current theories dealing with the pathogenesis of rheumatic fever.

\section{BIBLIOGRAPHY}

1. Cheadle, W. B., The Harveian Lectures on The Various Manifestations of the Rheumatic State as Exemplified in Childhood and Early Life. London, 1889.

2. St. Lawrence, W., J. Am. Med. Assoc., 1922, lxxix, 2051. The Family Association of Cardiac Disease, Acute Rheumatic Fever and Chorea: A Study of One Hundred Families.

3. Faulkner, J. M. and White, P. D., J. Am. Med. Assoc., 1924, lxxxiii, 425. The Incidence of Rheumatic Fever, Chorea and Rheumatic Heart Disease, with Especial Reference to its Occurrence in Families.

4. Cohn, A. E., Am. Heart J., 1927, ii, 275. Heart Disease from the Point of View of the Public Health.

5. Opie, E. L. and McPhedran, F. M., Am. Rev. Tuberc., 1926, xiv, 347. The Contagion of Tuberculosis. Also J. Am. Med. Assoc., 1926, lxxxvii, 1549. Spread of Tuberculosis within Families. 
6. Fiessinger, C., Gaz. méd. de Paris, 1892, i, 160. Note sur l'épidémiologie du rhumatisme articulaire aigu.

7. Kollmann, Münch. med. Wchnschr., 1902, xlix, 1098. Zur Pathogenese des akuten Gelenkrheumatismus.

8. Edlefsen, Verhandl. d. Cong. f. inn. Med., 1885, iv, 323. Zur Statistik und Aetiologie des acuten Gelenkrheumatismus. Also Friedlander,-see discussion of Edlefsen's paper.

9. Grenet, M. H., Presse méd., 1915, xxiii ${ }_{2}$ 428. Recherches sur l'étiologie du rhumatisme articulaire aigu. La contagiosité du rhumatisme.

10. Fedeli, A. L., Gazz. d. osp., 1920, xli, 1123. Contributo allo studio della possibile contagiosità del reumatismo articolare acuto.

11. Herrmann, H., Münch. med. Wchnschr., 1924, lxxi, 330. Ein Beitrag zum , endemischen Auftreten der akuten rheumatischen Polyarthritis.

12. Hathaway, J. C., Minnesota Med., 1930, xiii, 37. Rheumatic Fever: A Communicable Disease.

13. Andrieu, G., 1926, Toulouse. Le Rhumatisme articulaire aigu. Maladie contagieuse.

14. Boas, E. P. and Schwartz, S. P., Am. Heart J., 1927, ii, 375. Some Modes of Infection in Rheumatic Fever.

15. Hiller, R. I. and Graef, I., Am. Heart J., 1927-28, iii, 271. An Epidemic of Rheumatism at a Cardiac Camp.

16. Draper, G., Am. J. Med. Sci., 1926, clxxi, 803. Studies in Human Constitution. II. Heredity and Environment-The Disease Makers.

17. Hammerschlag, E., Wien. Arch. f. inn. Med., 1926-27, xiii, 361. Utber die konstitutionelle Disposition zum akuten Gelenkrheumatismus.

18. Miller, R., Supplement Brit. Med. J., 1926 (July 3rd), p. 5. Report on the Environmental and other Predisposing Causes of Rheumatic Infection. Also Lancet, 1928, i, 1005. The Influence of Environment on Rheumatic Infection.

19. Glover, J. A., Lancet, 1930, 1, 499. Milroy Lectures on the Incidence of Rheumatic Diseases. I. The Incidence of Acute Rheumatism.

20. Clarke, J. Tertius, J. Trop. Med., 1930, xxxiii, 249. The Geographical Distribution of Rheumatic Fever.

21. Sehlbach, A., Münch. med. Wchnschr., 1906, liii, 171. Ein Beitrag zur Pathogenese des akuten Gelenkrheumatismus.

22. Thomson, A. P., Arch. Dis. Childhood, 1928, iii, 20. A Study of the Distribution of Rheumatic Infection in Birmingham.

23. Campbell, M. and Warner, E. C., Lancet, 1930, i, 61. A Study of Rheumatic Disease in Children.

24. Swift, H. F., J. Am. Med. Assoc., 1929, xcii, 2071. Rheumatic Fever.

25. Zinsser, H., and Yu, H., Arch. Int. Med., 1928, xlii, 301. The Bacteriology of Rheumatic Fever and the Allergic Hypothesis.

26. Paul, J. R., J. Clin. Invest., 1931, x, 53. Age Susceptibility to Familial Rheumatic Infection. 